Article

\title{
High-Performance Lithium Sulfur Batteries Based on Multidimensional Graphene-CNT-Nanosulfur Hybrid Cathodes
}

\author{
Álvaro Doñoro ${ }^{1,2}$, Álvaro Muñoz-Mauricio ${ }^{3}$ and Vinodkumar Etacheri $1, *$ (D) \\ 1 Electrochemistry Division IMDEA Materiales, c/ Eric Kandel 2, Getafe, 28906 Madrid, Spain; \\ alvaro.donoro@imdea.org \\ 2 Facultad de Ciencias, Universidad Autónoma de Madrid, Cantoblanco, 28049 Madrid, Spain \\ 3 Escuela Politécnica Superior, Universidad Carlos III de Madrid, Leganés, 28911 Madrid, Spain; \\ amunozmauricio@gmail.com \\ * Correspondence: vinodkumar.etacheri@imdea.org; Tel.: +34-91-550-30-47
}

Citation: Doñoro, Á.;

Muñoz-Mauricio, Á.; Etacheri, V.

High-Performance Lithium Sulfur

Batteries Based on Multidimensional Graphene-CNT-Nanosulfur Hybrid Cathodes. Batteries 2021, 7, 26.

https://doi.org/10.3390/batteries 7020026

Academic Editor: Tobias Placke

Received: 2 March 2021

Accepted: 7 April 2021

Published: 19 April 2021

Publisher's Note: MDPI stays neutral with regard to jurisdictional claims in published maps and institutional affiliations.

Copyright: (C) 2021 by the authors. Licensee MDPI, Basel, Switzerland. This article is an open access article distributed under the terms and conditions of the Creative Commons Attribution (CC BY) license (https:/ / creativecommons.org/licenses/by/ $4.0 /)$.

\begin{abstract}
Although lithium-sulfur (Li-S) batteries are one of the promising candidates for nextgeneration energy storage, their practical implementation is limited by rapid capacity fading due to lithium polysulfide (LiPSs) formation and the low electronic conductivity of sulfur. Herein, we report a high-performance lithium-sulfur battery based on multidimensional cathode architecture consisting of nanosulfur, graphene nanoplatelets (2D) and multiwalled carbon nanotubes (1D). The ultrasonic synthesis method results in the generation of sulfur nanoparticles and their intercalation into the multilayered graphene nanoplatelets. The optimized multidimensional graphene-sulfur-CNT hybrid cathode (GNS58-CNT10) demonstrated a high specific capacity (1067 mAh g $\mathrm{m}^{-1} 50 \mathrm{~mA} \mathrm{~g}^{-1}$ ), rate performance (539@ $1 \mathrm{~A} \mathrm{~g}^{-1}$ ), coulombic efficiency ( 95\%) and cycling stability (726 $\mathrm{mAh} \mathrm{g}^{-1}$ after 100 cycles @ $200 \mathrm{~mA} \mathrm{~g}^{-1}$ ) compared to the reference cathode. Superior electrochemical performances are credited to the encapsulation of nanosulfur between the individual layers of graphene nanoplatelets with high electronic conductivity, and effective polysulfide trapping by MWCNT bundles.
\end{abstract}

Keywords: lithium-sulfur batteries; graphene nanoplatelets; carbon nanotubes; hybrid electrode

\section{Introduction}

High performance batteries are a key component for the efficient utilization of renewable energy [1-3]. Secondary lithium-ion (Li-ion) batteries have attracted huge interest due to their superior energy/power densities and cycling life in contrast to nickel-cadmium $(\mathrm{Ni}-\mathrm{Cd})$ and nickel-metal hydride $(\mathrm{Ni}-\mathrm{MH})$ batteries [4]. However, its performance matrices are not sufficient for many applications, including long range driving [5]. Many approaches, such as designing high-capacity electrodes, engineering electrolyte compositions and design optimizations, have been investigated previously for improving the electrochemical performance of Li-ion batteries [6,7]. Nevertheless, the energy and power density of this battery system has reached its limit, and the development of novel secondary batteries is necessary. Lithium-sulfur (Li-S) batteries are potential candidates for overcoming the gravimetric and volumetric energy density limitations of current generation Li-ion batteries [8-10]. The high theoretical capacities of sulfur cathode (1675 $\left.\mathrm{mAh} \mathrm{g}^{-1}\right)$ and lithium metal anode (3861 $\mathrm{mAh} \mathrm{g}^{-1}$ ) result in a high theoretical energy density of $2600 \mathrm{Wh} \mathrm{kg}^{-1}$, which greatly exceeds that of commercial Li-ion batteries [11].

Nevertheless, the low electronic conductivity of sulfur $\left(5 \times 10^{-30} \mathrm{~S} \mathrm{~cm}^{-1}\right.$ at $\left.25{ }^{\circ} \mathrm{C}\right)$, volume expansion during lithiation (70 to $80 \%$ ), and lithium polysulfide (LiPSs) formation/shuttling challenges the electrochemical performance and commercialization of Li-S batteries [9,12-16]. Consequently, numerous methods have been developed to overcome the shortcomings of current generation Li-S batteries $[10,17,18]$. Various strategies involved the use of electrolyte additives, highly concentrated electrolytes, carbon interlayers, 
and coating metal oxides on the cathode surface [9,19-22]. Additionally, conventional Li-ion battery cathode materials were also proven to be efficient for the mitigation of polysulfides. Recently, Zhang et al. developed a high-performance hybrid sulfur cathode, where lithium cobalt oxide $\left(\mathrm{LiCoO}_{2}, \mathrm{LCO}\right)$ was simply added to the cathode to extensively reduce the electrode degradation [23]. Only $3 \mathrm{wt} \%$ of LCO was enough to ensure a strong chemical interaction with LiPSs. Coating of sulfur-carbon hybrid cathodes with metal oxides such as $\mathrm{SiO}_{2}, \mathrm{Co}_{3} \mathrm{O}_{4}, \mathrm{TiO}_{2}$, and $\mathrm{Al}_{2} \mathrm{O}_{3}$ was also demonstrated to be efficient to improve the electrochemical performance [24-26]. One of the most commonly used and first demonstrated strategy is the fabrication of carbon-sulfur hybrid electrodes. This method enhanced the electronic conductivity of sulfur and reduced the polysulfide shuttling issue [27-32]. Several sulfur composite cathodes composed of carbon black, porous carbons, carbon nanospheres, carbon nanotubes (CNTs), and graphene/graphene oxide were investigated $[18,27,32-49]$. The electrode architecture of sulfur-carbon hybrid cathode also played a key role in deciding their electrochemical behavior. A combination of two-dimensional (2D) graphene and one-dimensional (1D) CNTs emerged as a possible design to overcome the inherent obstacles of Li-S batteries through their highly interconnected nano- and microstructure [50-56]. Despite these rational designs and good electrochemical results, these hybrid electrodes involve complex and time-consuming synthetic methods that cannot meet the large-scale production requirements $[55,57]$. For instance, melt-diffusion and hydrothermal/solvothermal methods involve the use of high-pressure containers and organic solvents that are not suitable for scale-up [58]. Carbonaceous materials used in these hybrid electrodes are also often expensive, which limits their use in real-world applications [59]. The design and fabrication of inexpensive and high-performance sulfur cathodes thus remains as a challenge for the commercialization of Li-S batteries.

Consequently, developments of new cost-effective and scalable synthetic methods for sulfur-carbon hybrid cathodes are necessary. Weng et al. reported an aqueous ultrasoundassisted method for the synthesis of carbon-sulfur hybrid electrodes [60]. Sonochemical reaction involves the fast $(<\mathrm{ns})$ generation and collapse of bubbles, resulting in high temperature $(\sim 5000 \mathrm{~K})$, pressure $\left(\sim 1000 \mathrm{~atm}\right.$.) and heating/cooling rates $\left(\sim 10^{10} \mathrm{~K} \mathrm{~s}^{-1}\right)[61,62]$. This promotes the redox reactions at the molecular level, resulting in the formation of colloidal sulfur [62,63]. Ultrasonic treatment is also beneficial for the uniform dispersion of nanosulfur in the carbon matrix [64]. Sonochemical synthetic methods are known to have high efficiency, kinetics and yield in comparison to the conventional processes [61]. Previously reported sonochemical synthetic methods often resulted in the surface decoration of two-dimensional and porous carbon matrix without involving any mechanical/chemical interaction with sulfur nanoparticles $[24,60,65]$. Protection of sulfur nanoparticles in the carbon matrix from the electrolyte attack is crucial to obtain enhanced electrochemical performance [66]. Despite the numerous advantages of sonochemical methods, carbon-sulfur hybrid electrodes obtained through this method exhibited mediocre electrochemical performance. Hong et al. demonstrated further improvement of the electrochemical performance through atomic layer deposition (ALD) coating of $\mathrm{Al}_{2} \mathrm{O}_{3}$ on graphene-sulfur hybrid cathode prepared through the sonochemical method [24]. Such sophisticated coating techniques are expensive and difficult to scale-up for commercial applications. It is thus clear that additional strategies need to be implemented to further improve the performance of carbon-sulfur hybrids obtained through sonochemical synthetic methods.

Herein, we report a multidimensional electrode architecture, composed of nanosulfur, graphene nanoplatelets (2D) and multiwalled carbon nanotubes (1D). The synthetic method involves an aqueous sonochemical method, where sulfur nanoparticles are generated through the reduction of sodium thiosulfate (Figure 1a). The intercalation of sulfur nanoparticles between the individual graphene layers is also achieved by this method. Individual components of the multidimensional hybrid cathode are carefully chosen to enhance the electrochemical performance of the Li-S battery. Nanosized sulfur is selected as the active material to overcome the poor conductivity of bulk sulfur. Multilayered graphene nanoplatelets are aimed at improving the overall electronic conductivity of electrodes, 
accommodating volume expansion and protecting nanosulfur from electrolyte attack and thereby minimizing polysulfide shuttling. Multiwalled carbon nanotubes (MWCNTs) are used as additives to improve the electronic conductivity and as a polysulfide absorber to effectively mitigate their shuttling between electrodes during the charge-discharge process. Careful engineering of such a hybrid multidimensional sulfur cathode resulted in the superior electrochemical performance of Li-S battery.
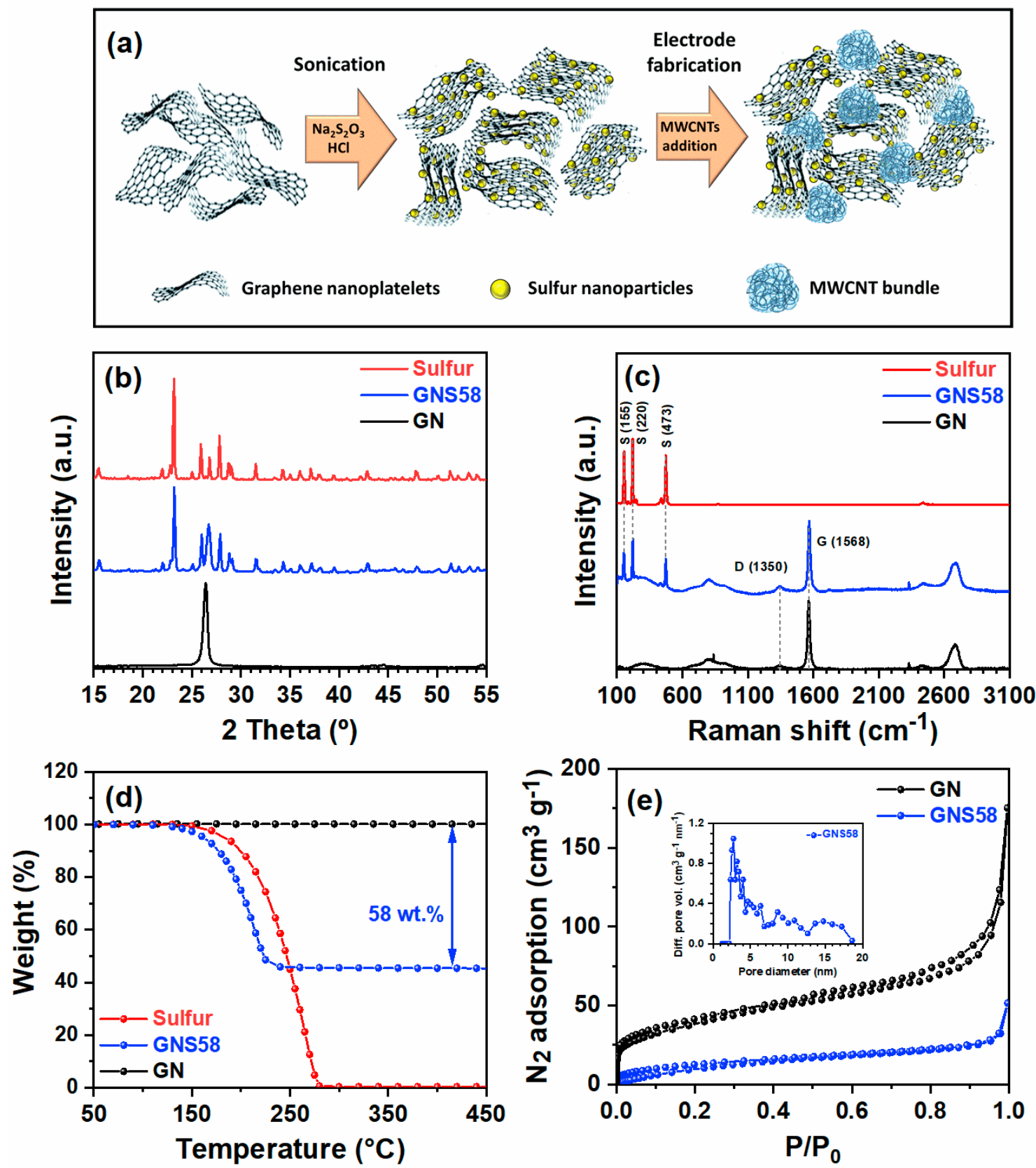

Figure 1. (a) Schematic of the synthesis of multidimensional GNS58-CNT10 hybrid cathode. (b) X-ray diffraction patterns, (c) thermogravimetric analysis and (d) Raman spectra of graphene nanoplatelets, elemental sulfur and GNS58 powder. (e) $\mathrm{N}_{2}$ adsorption-desorption isotherms of graphene nanoplatelets and GNS58 powder and pore size distribution of GNS58 (inset). 


\section{Results and Discussion}

\subsection{Synthesis and Characterization of Graphene-CNT-Nanosulfur Hybrid Cathode}

The synthesis method of multilayered graphene nanoplatelets-nanosulfur hybrid is achieved through a one-step sonochemical method. As mentioned earlier, the sonochemical synthesis method involves acoustic cavitation and results in local temperature/pressure increase [61]. This causes the in-situ reduction of sodium thiosulfate $\left(\mathrm{Na}_{2} \mathrm{~S}_{2} \mathrm{O}_{3}\right)$ in aqueous media into elemental sulfur $\left(\mathrm{S}^{0}\right)$ in the form of sulfur nanoparticles $[24,60]$. Dilute hydrochloric acid and hydroxide/hydronium ions formed by the sonication of water molecules also aid the generation of elemental sulfur nanoparticles $\left(\mathrm{Na}_{2} \mathrm{~S}_{2} \mathrm{O}_{3}+2 \mathrm{HCl}+\mathrm{H}^{+}+\mathrm{OH}^{-} \rightarrow\right.$ $2 \mathrm{NaCl}+\mathrm{H}_{2} \mathrm{O}+\mathrm{S}^{0}+\mathrm{SO}_{2}$ ) [60]. Generated colloidal sulfur nanoparticles are uniformly decorating the multilayered graphene nanoplatelets. Ultrasound irradiation plays multiple roles in the demonstrated synthesis procedure. It is (1) essential to disperse the nanoplatelets in the aqueous reaction medium, (2) promote the reduction reaction of $\mathrm{Na}_{2} \mathrm{~S}_{2} \mathrm{O}_{3}$ to sulfur nanoparticles, and (3) partially exfoliate the multilayered graphene nanoplatelets to enable the intercalation of sulfur nanoparticles [24,60]. Multilayered graphene nanoplatelets are selected as the carbon matrix due to their inexpensive nature compared to single-layered graphene, high electronic conductivity, and possible intercalation of nanosulfur between the interlayers [67]. The FTIR pattern of graphene nanoplatelets (Figure S1) demonstrates the absence of functional groups, which proves the lack of sulfur interaction with the graphene surface through chemical bond formation. Such intercalation of nanosulfur is advantageous to accommodate the volume change during the charge-discharge process. Graphene nanoplatelets also mitigate the low electronic conductivity of sulfur in addition to protecting it from electrolyte attack. MWCNT clusters are used instead of expensive SWCNTs to further immobilize polysulfides, which can further improve the electrochemical performance. It is worth noting that previous works reported in the literature typically depend on complex synthetic methods including multiple steps. In fact, most of them firstly report the synthesis of graphene or graphene oxide as a carbon matrix in order to further combine it with MWCNT or SWCNT to achieve a multidimensional architecture [50,51,68-72]. The SWCNTs used in the literature are also expensive, which limit their large-scale application. Therefore, our cathode design utilizing cheaper graphene nanoplatelets, MWCNT bundles, and a scalable ultrasonic method successfully overcomes the inherent synthetic and application limitations mentioned above.

The X-ray diffraction (XRD) pattern (Figure 1b) of graphene nanoplatelets-nanosulfur hybrid containing 58\% sulfur (GNS58) showed characteristic signals at 15.3, 23.08, 25.8, 31.4 and $37.0^{\circ}$ that correspond to the (113), (222), (026), (044) and (317) planes of an orthorhombic $\alpha$-sulfur phase [73]. The average size of sulfur nanoparticles $(\sim 23 \mathrm{~nm})$ is calculated from the Debye-Scherrer formula using the (222) Bragg reflection at $23.1^{\circ}$. Considering that the calculated size ranges between 10 to $100 \mathrm{~nm}$, small sulfur particles can be categorized as ultrafine particles or microcrystals [74,75]. Additionally, GNS58 showed a characteristic peak at $26.7^{\circ}$ (Figure S2) which is upshifted compared to graphene nanoplatelets $\left(2 \theta=26.4^{\circ}\right)$. This minor change in the diffraction peak positions can be related to the strong carbon-sulfur affinity resulting from the intercalation of sulfur nanoparticles between the individual layers. In both cases, said diffraction peaks represent slightly different d-spacing ( $0.33 \mathrm{~nm}$ for GNS58 and $0.34 \mathrm{~nm}$ for graphene nanoplatelets), which corresponds to the 002 crystal plane of graphite [76]. These XRD patterns also confirmed a highly graphitized structure, and stacking of several graphene layers [76]. Raman spectra (Figure 1c) of GNS58 exhibited signals corresponding to multilayered graphene nanoplatelets and sulfur nanoparticles. The D-band at $1350 \mathrm{~cm}^{-1}$ refers to the defects and disorder of the carbon 
structure, while the G-band at $1568 \mathrm{~cm}^{-1}$ corresponds to the presence of $\mathrm{sp}^{2}$ hybridized carbon structure of graphene nanoplatelets [77]. Moreover, the ID/IG ratios (0.06 for graphene nanoplatelets vs. 0.15 for GNS58) prove that the disorder of commercial graphene nanoplatelets is slightly increased during the ultrasonic treatment, which is to be expected due to the high energy created during the cavitation process [61,78]. This also confirmed the intercalation of sulfur nanoparticles between the graphene layers of the nanoplatelets [60]. Raman signals located at $155 \mathrm{~cm}^{-1}$ and $220 \mathrm{~cm}^{-1}$ are characteristic of $S_{8}$ bending [79].

The presence of sulfur nanoparticles is also verified by the S-S bond stretching signal at $473 \mathrm{~cm}^{-1}$ [79]. Thermogravimetric analysis (TGA) of GNS58 is employed to quantify the sulfur loading in the hybrid (Figure 1d). Single-step evaporation of $58 \mathrm{wt} \%$ sulfur at around $200{ }^{\circ} \mathrm{C}$ is a clear evidence of the homogeneous distribution of sulfur nanoparticles in the graphene-sulfur composite [60]. An uneven particle size distribution can be ruled out in this case by the lack of multiple weight loss steps. This clearly demonstrated the efficiency of the sonochemical method to generate sulfur nanoparticles of uniform size distribution.

Textural property measurements (Figure 1e), through nitrogen adsorption-desorption analysis, verified the reduction of both micropores and BET external surface area of the graphene nanoplatelets $\left(59.7 \mathrm{~m}^{2} \mathrm{~g}^{-1}\right.$ and $79.9 \mathrm{~m}^{2} \mathrm{~g}^{-1}$, respectively) after sonochemical reaction $\left(15.7 \mathrm{~m}^{2} \mathrm{~g}^{-1}\right.$ and $34.9 \mathrm{~m}^{2} \mathrm{~g}^{-1}$, respectively), demonstrating that sulfur nanoparticles are not just sonochemically inserted between the graphene layers, but they are also covering the surface of the graphene nanoplatelets. The Barrett-Joyner-Halenda (BJH) pore-size distribution of the graphene nanoplatelets-sulfur hybrid (Figure 1e inset) confirmed the presence of mesopores that can be caused by the inner cavities formed between stacks of graphene sheets and the spacing between individual sheets [80]. The presence of such mesopores in the sulfur hybrid cathode is beneficial to achieve improved charge transfer kinetics resulting from the superior contact with the electrolyte solution [81]. Morphological characterization through SEM (Figure 2a,b) confirmed the presence of micron-sized graphene platelets. Sulfur nanoparticles are not visible in these images due to their ultrafine size. MWCNT bundles are clearly visible in the case of the GNS58-CNT10 sample (Figure 2c,d), depicting their successful incorporation with graphene nanoplatelets in the electrode structure. It is worth noting that the morphology of graphene nanoplatelets (Figure S3) is preserved during the sonochemical reaction. Further morphological studies using TEM confirmed the presence of ultrafine sulfur nanoparticles (Figure 2e) uniformly decorated on the graphene nanoplatelets. The homogeneous distribution of sulfur nanoparticles is also evident from the EDX elemental mapping (Figure $2 \mathrm{f}-\mathrm{i}$ ). It should be noted that the entire graphene nanoplatelet surface is not covered with sulfur nanoparticles, which is crucial for maintaining good electronic conductivity. Ultrafine sulfur nanoparticles and a low degree of agglomeration is beneficial for reduced charge transfer resistance. Hence, it is clear that the aqueous sonochemical synthetic method results in the formation of graphene nanoplatelets-nanosulfur hybrid. 

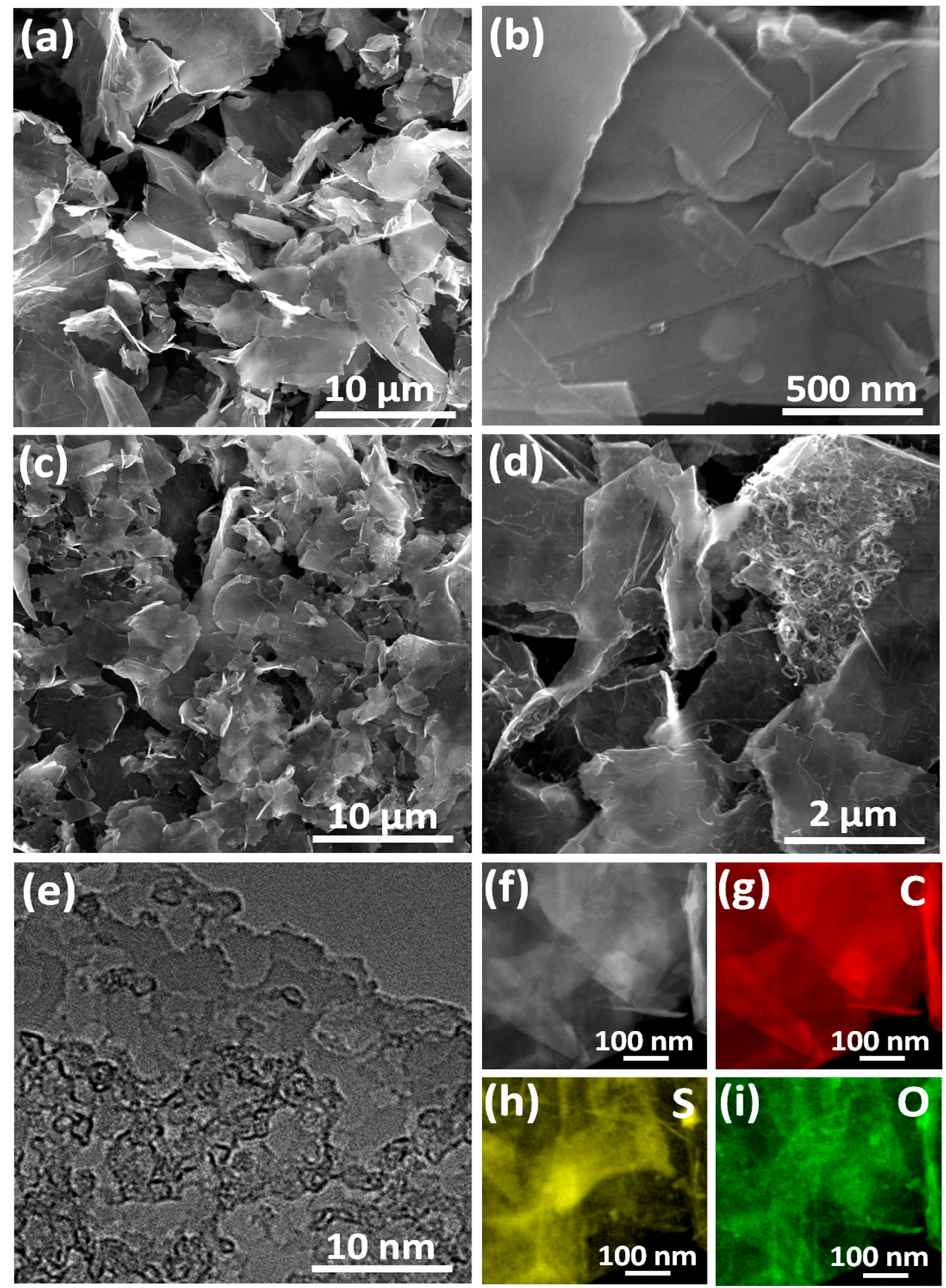

Figure 2. SEM images of (a,b) GNS58 powder and (c,d) GNS58-CNT10 hybrid cathode at various magnifications (e) TEM image of GNS58 powder. (f) HAADF image, and (g-i) corresponding EDX elemental mapping of GNS58 powder. 


\subsection{Electrochemical Performance Evaluation of Hybrid Cathode}

The lithium-ion storage performance of both CNT-free and CNT-containing cathode compositions were tested in 2032 type coin cells composed of Li-metal foil reference/counter electrode and $\mathrm{LiTFSI}_{-} \mathrm{LiNO}_{3}-\mathrm{DOL} / \mathrm{DME}$ electrolyte solution. Figure S4 represents the first and second galvanostatic charge-discharge voltage profiles of GNS58 and the electrochemically most active GNS58-CNT10 cathodes at different current densities. The enhanced specific capacities and rate performance are observed for the GNS58-CNT10 cathode compared to GNS58 (Figure 3a,b). CNT-free GNS58 exhibited a specific capacity of $833 \mathrm{mAh} \mathrm{g}^{-1}$ at a current density of $50 \mathrm{~mA} \mathrm{~g}^{-1}$, which is $\sim 22 \%$ lower than those of GNS58-CNT10 (1067 $\left.\mathrm{mAh} \mathrm{g}^{-1}\right)$. Increased specific capacity differences are observed at higher current densities. For instance, at a current density of $1 \mathrm{~A} \mathrm{~g} \mathrm{~g}^{-1}$, GNS58 and GNS58CNT10 delivered specific capacities of 330 and $544 \mathrm{mAh} \mathrm{g}^{-1}$, respectively. Analysis of the voltage profiles indicated the formation of short-chain LiPSs at 2.1 V. This plateau of the GNS58 cathode decreased $\sim 66 \%$ ( 549 to $184 \mathrm{mAh} \mathrm{g}^{-1}$ ) upon increasing the current $50 \mathrm{~mA} \mathrm{~g}^{-1}$ to $1 \mathrm{Ah} \mathrm{g}^{-1}$, while only $\sim 45 \%$ loss is observed in the case of GNS58-CNT10 (663 to $302 \mathrm{mAh} \mathrm{g}^{-1}$ ). The second reduction region of the discharge profile is always larger for the GNS58-CNT10 than GNS58 ( 21\% larger @ $50 \mathrm{~mA} \mathrm{~g}^{-1}$ and 65\% larger @ $1 \mathrm{~A} \mathrm{~g}^{-1}$ ). This clearly demonstrates the improved sulfur utilization of CNT-containing cathode composition compared to GNS58, and stabilization of $\mathrm{Li}_{2} \mathrm{~S}_{2} / \mathrm{Li}_{2} \mathrm{~S}$ irrespective of the current density. When compared to GNS58, smaller voltage hysteresis corresponding to the voltage profile of GNS58-CNT10 (Figure 3a,b) evinces enhanced Li-ion transport through the SEI formed in the presence of MWCNT bundles. The first cycle-specific capacities of these electrodes also followed the same trend. The electrochemical performances of GNS58 are superior to the composite electrode containing only carbon black, bulk sulfur and nanosulfur. This clearly demonstrates the positive effect of nanosulfur, graphene nanoplatelets and MWCNT bundles towards improving the electrochemical performance. It should also be noted that the use of only nanosulfur or graphene platelets is not sufficient to considerably enhance the performance. The rate performance and specific capacities also highly depended on the CNT loading (Figure S5b), and performance decreased after an optimum content of $10 \mathrm{wt} \%$. Cyclic voltammograms of both GNS58 and GNS58-CNT10 (Figure $3 \mathrm{c}, \mathrm{d}$ ) were recorded in order to follow the redox process of nanosulfur during the charge-discharge process. As expected, both electrodes exhibited cathodic peaks around $2.3 \mathrm{~V}$ and $2.0 \mathrm{~V}$ due to the conversion of nanosulfur to long-chain and short-chain LiPSs, respectively. Corresponding anodic peaks at around $2.3 \mathrm{~V}$ and $2.4 \mathrm{~V}$ indicated the reversible conversion of LiPSs to sulfur. It is worth noting that the redox signals are sharper and more intense for GNS58-CNT10 compared to the broader peaks of GNS58. A minor downshifting of redox potentials for GNS58-CNT10 in contrast to GNS58 is also observed. This can be credited to the difference in sulfur redox kinetics due to the presence of MWCNT bundles that can possibly interact with LiPSs. 

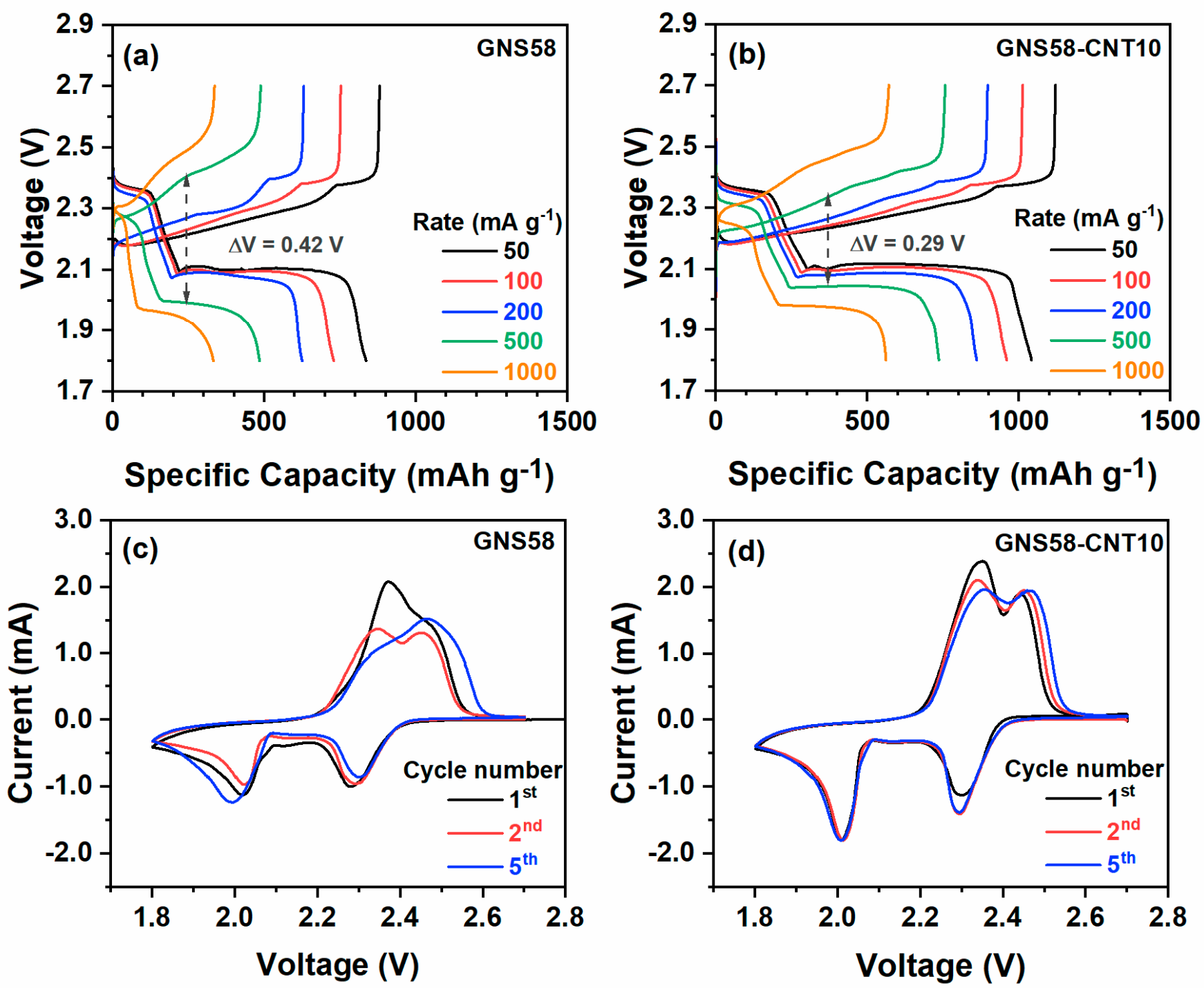

Figure 3. Galvanostatic charge-discharge profiles of (a) GNS58 and (b) GNS58-CNT10 hybrid cathodes at different current densities. Cyclic voltammograms of (c) GNS58 and (d) GNS58-CNT10 cathodes at a scan rate of $0.1 \mathrm{mV} \mathrm{s}^{-1}$.

Sulfur cathodes containing $5 \mathrm{wt} \%$ (GNS58-CNT5) and $10 \mathrm{wt} \%$ (GNS58-CNT10) MWCNT compositions were tested and compared with GNS58. Several reference electrodes were fabricated and tested to provide a thorough comparison with the used synthetic method and multidimensional electrode composition. While CBS58 was prepared by using the same ultrasound-assisted method, BulkGNS58 and BulkCBS58 consist of mechanically mixed compositions. Moreover, CBS58, BulkGNS58 and BulkCBS58 differ on the carbon matrix (carbon black or graphene nanoplatelets) and sulfur morphology (nanoparticles or bulk). Galvanostatic rate performances (Figure 4a) prove both the effect of carbon matrix and MWCNT loading on the electrochemical performance. As expected, the reference cathode CBS58 exhibited the lowest rate performance due to the use of carbon black instead of graphene nanoplatelets. GNS58 delivered a specific capacity of around $833 \mathrm{mAh} \mathrm{g}^{-1}$ at a current density of $50 \mathrm{~mA} \mathrm{~g}^{-1}$, much lower than those of GNS58-CNT5 $\left(1000 \mathrm{mAh} \mathrm{g}^{-1}\right)$ and GNS58-CNT10 (1067 $\left.\mathrm{mAh} \mathrm{g}^{-1}\right)$ at identical testing conditions. A similar trend is observed at a high current density of $1 \mathrm{~A} \mathrm{~g}^{-1}$, where MWCNT-containing cathodes showed specific capacities between 450 and $550 \mathrm{mAh} \mathrm{g}^{-1}$. The MWCNT-free GNS58 cathode leads to a low specific capacity $\left(\sim 300 \mathrm{mAh} \mathrm{g}^{-1}\right)$ under similar experimental conditions. Furthermore, MWCNT modified electrodes recovered most of their original specific capacities upon reducing the current density to $50 \mathrm{~mA} \mathrm{~g}^{-1}$. Nanosulfur also played a crucial role in 
the electrochemical performance of carbon-sulfur hybrid cathodes (Figure S5a). Hence, both CBS58 and GNS58 electrodes exhibited superior performance compared to their corresponding counterparts containing bulk sulfur (Figure S6). In fact, GNS58 delivered a three-fold higher specific capacity than BulkGNS58 (315 $\mathrm{mAh} \mathrm{g}^{-1}$ vs. $96 \mathrm{mAh} \mathrm{g}^{-1}$ ) electrode at a high current density of $1 \mathrm{~A} \mathrm{~g}^{-1}$. When bulk sulfur is mixed with either carbon black (BulkCBS58) or graphene nanoplatelets (BulkGNS58), sulfur integration within the carbon host is mostly superficial, meaning that sulfur is fully exposed to the electrolyte and the corresponding shuttle effect seriously affects the battery performance. From these results, it can be deduced that higher electronic conductivity of graphene allows the use of bulk sulfur to achieve high performance at low current densities compared to BulkCBS58 electrode (800 $\mathrm{mAh} \mathrm{g}^{-1}$ vs. $665 \mathrm{mAh} \mathrm{g}^{-1}$ at $50 \mathrm{~mA} \mathrm{~g}^{-1}$ ).
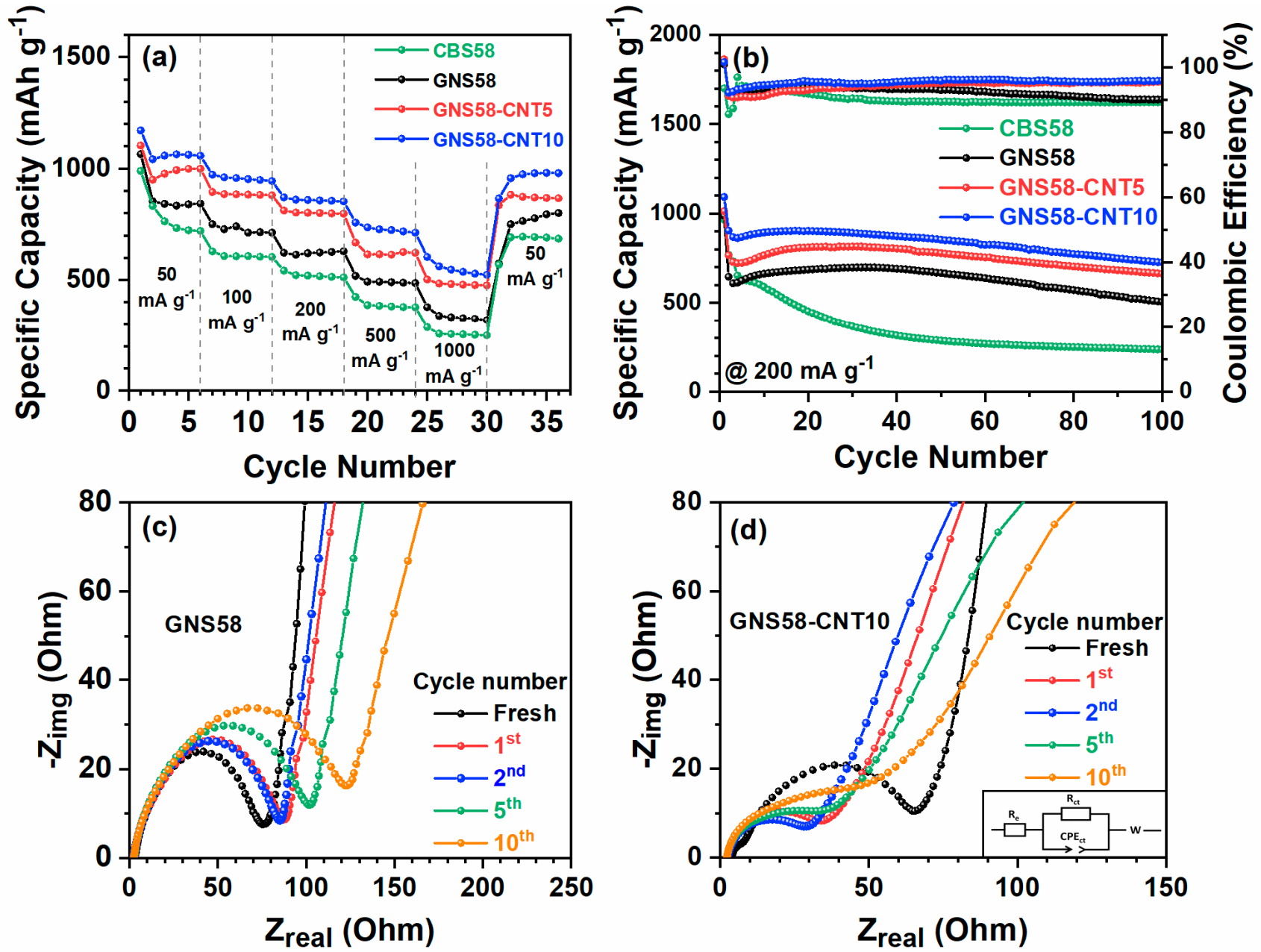

Figure 4. (a) Galvanostatic rate performance, and (b) cycling performance of GNS58, GNS58-CNT5 and GNS58-CNT10 cathodes. Nyquist plot of (c) GNS58 and (d) GNS58-CNT10 cathodes. Inset: equivalent circuit model used for fitting the EIS spectra. 
However, the porous carbon black of the BulkCBS58 electrode seems to prevail over the electronic properties of graphene in BulkGNS58 at higher current densities $\left(135 \mathrm{mAh} \mathrm{g}^{-1}\right.$ vs. $96 \mathrm{mAh} \mathrm{g}^{-1}$, respectively, at $1 \mathrm{~A} \mathrm{~g}^{-1}$ ). Significant improvement in the electrochemical performance can be observed when nanosulfur is used instead of bulk sulfur. Nanosulfur particles can be fully integrated into the carbon host due to their reduced size, resulting in reduced exposure to the electrolyte solution. Consequently, enhanced electrochemical performances are obtained at all tested current densities. Galvanostatic performance of GNS58 exhibited 20\% improvement at both low and high current densities, confirming that graphene nanoplatelets play an essential role in the excellent performance of the GNS58 cathode. The electrochemical performance of cathode compositions containing different MWCNT loading confirmed $10 \mathrm{wt} \%$ as the optimum (Figure S5b) content. It is worth noting that the electrochemical performance of the GNS58-CNT10 cathode is able to match the previous reports of CNT-graphene-sulfur hybrid composites [68,70]. In fact, the graphene nanoplatelets-MWCNT carbon matrix in GNS58-CNT10 even delivered superior initial cycling stability compared to three-dimensional graphene nanosheet@carbon nanotube matrices [71]. Some research have even tried to improve the electrochemical performance of their graphene/CNT materials by including additional components, such as molybdenum nanoparticles [82]. However, despite their good electrochemical results, we strongly believe that the highly complex multistep synthesis of the host material lacks the feasibility for scale-up industrialization, which is one of the main motivations for the simplicity of our GNS58-CNT10 cathode.

The effect of the MWCNT additive on the long-term cycling stability is also studied at a current density of $200 \mathrm{~mA} \mathrm{~g}^{-1}$ (Figure $4 \mathrm{~b}$ ). After delivering initial discharge capacities of 1000 and $1100 \mathrm{mAh} \mathrm{g}^{-1}$, specific capacities of GNS58 and GNS58-CNT5 stabilized at 698 and $815 \mathrm{mAh} \mathrm{g}^{-1}$, respectively, after 30 cycles. While GNS58-CNT10 took only 20 cycles to stabilize at a discharge capacity of $900 \mathrm{mAh} \mathrm{g}^{-1}$, GNS58 exhibited poor capacity retention, delivering only $505 \mathrm{mAh} \mathrm{g}^{-1}$ after 100 cycles. On the contrary, MWCNT-containing electrodes performed better, delivering specific capacities of 663 and $726 \mathrm{mAh} \mathrm{g}^{-1}$ for GNS58-CNT5 and GNS58-CNT10, respectively. While capacity decay after cell stabilization is reduced from $0.40 \%$ per cycle to $0.24 \%$ for GNS58 and GNS58-CNT10, respectively, coulombic efficiencies are also increased for MWCNT containing electrodes. CNT-free GNS58 electrode delivered a coulombic efficiency of $90 \%$, whereas both GNS58-CNT5 and GNS58-CNT10 exhibited coulombic efficiencies of around 95\%. According to these results, it is clear that MWCNT bundles play a crucial role in the increase of specific capacities, rate performance, coulombic efficiency and cycling stability.

Electrochemical impedance spectroscopy (EIS) measurements are performed to further analyze the effect of MWCNT bundles on the electrochemical performance of Li-S cells. The Nyquist plots (Figure 4c,d) contain two semicircles-one at the high-frequency region indicating the electrolyte resistance (Re), and another one at the medium-frequency range associated with the charge-transfer resistance (Rct). The slanting line at the low-frequency region corresponds to the Warburg impedance (W), as shown at the inset of Figure 4d [51]. Since graphene nanoplatelets and nanosulfur are implemented in both GNS58 and GNS58CNT10 electrodes, and the same electrolyte solutions are used in both cases, differences in impedance behavior are a consequence of the CNT addition. Charge transfer resistances of pristine GNS58 and GNS58-CNT10 electrodes are 75 and $65 \Omega$, respectively. The improved charge transfer of GNS58-CNT10 in this case can be attributed to improved conductivity and contact with the electrolyte solution resulting from the addition of MWCNT bundles. Different trends in the impedance variations are observed in the case of these carbon-sulfur hybrid cathodes upon the charge-discharge process. The charge transfer resistance of GNS58 increased considerably during galvanostatic cycling, whereas the GNS58-CNT10 
cathode displayed an opposite trend in the charge transfer resistance. After the first galvanostatic cycle, Rct of GNS58 increased to $85 \Omega$, and GNS58-CNT10 decreased to $34 \Omega$. Increased Rct of GNS58 after five and 10 cycles (102 and $123 \Omega$, respectively) in comparison to the GNS58-CNT10 electrode ( 35 and $47 \Omega$, respectively) are also observed. A considerable increase in the Rct of GNS58-CNT10 during the charge-discharge process can be related to the accumulation of insulating lithium sulfides $\left(\mathrm{Li}_{2} \mathrm{~S}\right.$ and $\left.\mathrm{Li}_{2} \mathrm{~S}_{2}\right)$ on the electrode surface. This results from the well-known polysulfide formation and shuttling between electrodes during the charge-discharge process. The MWCNT clusters effectively trap polysulfides, reducing their shuttling and accumulation on the surface, resulting in reduced charge transfer resistance during galvanostatic cycling. Li-ion diffusion coefficients of GNS58 and GNS58-CNT10 in pristine Li-S cells are $2.77 \times 10^{-12} \mathrm{~cm}^{2} \mathrm{~s}^{-1}$ and $2.25 \times 10^{-12} \mathrm{~cm}^{2} \mathrm{~s}^{-1}$, respectively. Diffusion coefficients of GNS58 remained almost the same during charge-discharge cycling, whereas, in the case of GNS58-CNT10, the diffusion coefficients increased during cycling $\left(3.74 \times 10^{-12} \mathrm{~cm}^{2} \mathrm{~s}^{-1}\right.$ after 10 cycles). This can be related to the preferential absorption of polysulfides by the MWCNT clusters, which facilitate superior Li-ion diffusion that is limited in the case of MWCNT-free compositions due to the surface accumulation of Li-polysulfides. These results are clear indications of superior Li-ion transport properties resulting from the presence of MWCNT bundles in the graphene nanoplatelets-sulfur hybrid cathode.

\subsection{Post-Cycling Analysis of Hybrid Cathode}

Post-cycling analysis of the electrodes confirmed our hypothesis that MWCNT bundles enhance the electrochemical performance of GNS58-CNT10 by acting as a LiPSs trap (Figure 5a). A SEM image of the GNS58-CNT10 cathode after the first 10 galvanostatic cycles is presented in Figure 5b. EDX elemental mapping (Figure 5c-e) demonstrated increased sulfur and fluorine concentration on MWCNT bundles compared to the graphene surface. High sulfur concentration is a clear indication of the preferential polysulfide accumulation on MWCNT bundles. Increased fluorine concentration can be ascribed to the formation of SEI containing fluorine-containing species resulting from LiTFSI decomposition. Hence, it is clear that MWCNT bundles act as both a polysulfide trap and SEI forming additive, reducing the charge transfer resistance. Both these processes enhance the electrochemical performance by reducing polysulfide shuttling. The enhanced electrochemical performance of GNS58-CNT10 can be credited to the unique multidimensional architecture composed of multilayered graphene nanoplatelets, nanosulfur and MWCNT bundles. Sulfur nanoparticles are generated and intercalated into the multilayered graphene platelets during the sonochemical synthetic method. Further performance enhancement is obtained by the addition of MWCNT bundles. In addition to acting as a polysulfide trap, interaction of electrolyte solution with CNT also facilitate the formation of SEI with improved Li-ion transport properties. Moreover, MWCNT clusters also reduce the deposition of insulating polysulfides on the cathode surface, resulting in enhanced charge transfer kinetics. In conclusion, multidimensional cathode architecture presented here is attractive for high-performance Li-S batteries. 

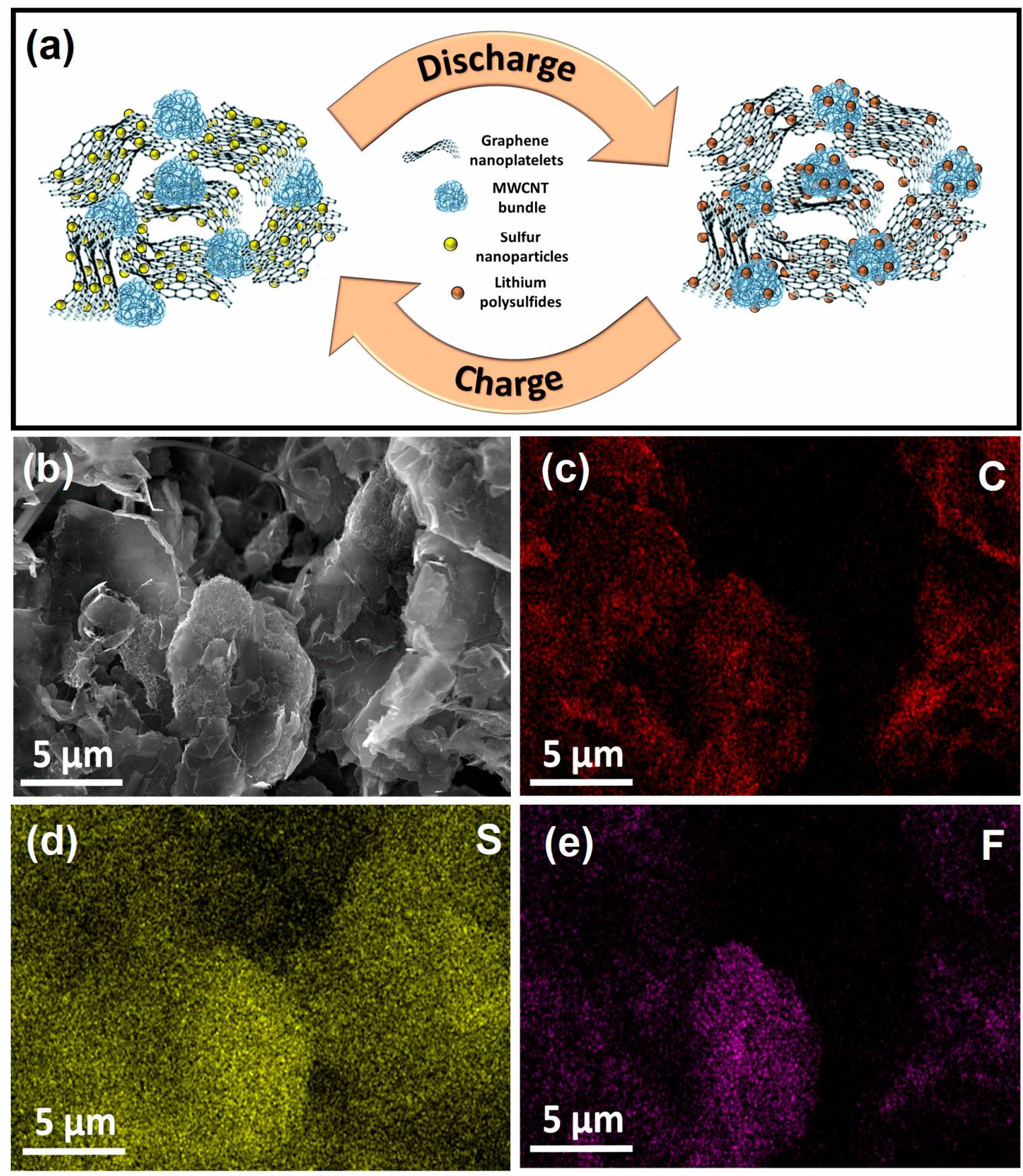

Figure 5. (a) Schematic representation of charge-discharge and polysulfide trapping mechanism in GNS58-CNT10 cathode. (b) SEM image and (c-e) EDX elemental mapping of cycled GNS58-CNT10 electrode.

\section{Materials and Methods}

\subsection{Material Synthesis}

A graphene nanoplatelets-nanosulfur hybrid containing 58\% nanosulfur (GNS58) was prepared through an ultrasonic method. In a typical synthesis, $1 \mathrm{~g}$ of graphene nanoplatelets ( $\sim 5 \mathrm{~m}$ width, Strem Chemicals, Newburyport, MA, USA) was dispersed in $100 \mathrm{~mL}$ of deionized water through ultrasonication $(20 \%$ intensity, $20 \mathrm{kHz})$ for $15 \mathrm{~min}$, followed by dissolving $9.8 \mathrm{~g}$ of sodium $\left(\mathrm{Na}_{2} \mathrm{~S}_{2} \mathrm{O}_{3}, 99 \%\right.$, Sigma Aldrich, St. Louis, MO, USA). Ultrasonic irradiation was also applied during the addition of dilute hydrochloric acid solution $(50 \% \mathrm{v} / \mathrm{v})$ into the obtained suspension. The resulting slurry was then washed four times with $100 \mathrm{~mL}$ of deionized water and $100 \mathrm{~mL}$ of ethanol (96\%, Sigma Aldrich). 
GNS58 was dried overnight at room temperature by spreading the final slurry over a surface, forming a thin film to facilitate solvent evaporation. As control samples for comparing the electrochemical performance, sulfur-carbon composites containing carbon particles (Acetylene black, MTI Corporation) and sulfur nanoparticles (CBS58) were prepared through the same method, while elemental sulfur was mechanically mixed with graphene nanoplatelets (BulkGNS58) or carbon particles (BulkCBS58) for further comparison.

\subsection{Material Characterization}

An Empyrean X-ray diffractometer (PANalytical) fitted with $\mathrm{Cu}-\mathrm{K} \alpha$ radiation was used for recording the X-ray diffraction (XRD) patterns $\left(2 \theta=10-80^{\circ}\right)$ of samples. The scattering angle $(\theta)$ has been converted to the distance between diffracting planes (d) according to the Bragg condition $(\mathrm{d}=\lambda /(2 \sin \theta)$. The sulfur particle size in GNS58 has been calculated according to the Debye-Scherrer equation $(D=K \lambda / \beta \cos \theta)$. The sulfur content of the composite was measured by carrying out thermogravimetric analysis (TGA) using a Q50 instrument (TA Instruments) in the temperature range of 25 to $400{ }^{\circ} \mathrm{C}$ under a $\mathrm{N}_{2}$ atmosphere (heating rate of $10{ }^{\circ} \mathrm{C} \mathrm{min}-1$ ). The specific surface area was calculated by using the multipoint Brunauer-Emmett-Teller (BET) method in a Micromeritics ASAP 2020 surface area analyzer. FEI Helios Nano-Lab 600i Dual-Beam was used to record scanning electron microscopy (SEM) images and energy dispersive X-ray spectroscopy (EDX) images. Raman spectral measurements were performed by a Renishaw PLC spectrometer equipped with a $532 \mathrm{~nm} \mathrm{Nd:} \mathrm{YAG} \mathrm{laser.} \mathrm{FTIR} \mathrm{spectrum} \mathrm{of} \mathrm{multilayered} \mathrm{graphene} \mathrm{nanoplatelets} \mathrm{in} \mathrm{the}$ attenuated total reflectance (ATR) mode was collected by employing a Thermo Scientific Nicolet iS50 spectrometer. Microstructural analysis and EDX elemental mapping of GNS58 were accomplished by using a FEI Talos F200X FEG high-resolution transmission electron microscope operating at $80 \mathrm{kV}$.

\subsection{Electrochemical Measurements}

Sulfur-carbon composite cathodes were fabricated by mixing GNS58 with various amounts of MWCNTs (TNIM4, Timesnano) and 10\% polyvinylidene fluoride (HSV900, MTI Corporation) in N-methylpyrrolidone (Sigma Aldrich) followed by coating on an aluminum foil. Electrodes were fabricated with an average area of $1.25 \mathrm{~cm}^{2}$ and a total composite loading of $\sim 4.0 \mathrm{mg}$ per electrode, representing a sulfur loading of $\sim 2.0 \mathrm{mg} \mathrm{cm}^{-2}$. Coin cells (2032 type) were assembled by using sulfur composite cathodes, Li-metal foil (99.99\%, MTI Corporation) anode and a glass fiber (GF/C grade, Sigma Aldrich) separator. The electrolyte consists of $1 \mathrm{M}$ lithium bis(trifluoromethanesulfonyl) imide (LiTFSI, 99.95\%, Sigma Aldrich) solution in a 1:1 $(v / v)$ mixture of 1,3-dioxolane (DOL, 99\%, Sigma Aldrich) and 1,2-dimethoxyethane (DME, 99.5\% Sigma Aldrich). Lithium nitrate ( $\mathrm{LiNO}_{3}, 98 \%$ Sigma Aldrich) was also used as an additive $(0.2 \mathrm{M})$. Each cell was fabricated with a total electrolyte amount of $70 \mu \mathrm{L}$, representing an electrolyte-to-sulfur ratio of $35 \mu \mathrm{L} \mathrm{mg}^{-1}$. All coincell fabrications were performed inside a glove box filled with ultra-high purity argon $(99.999 \%)$, and the content of oxygen and water were kept below 1 ppm. A Neware 4000 multi-channel battery tester system was used for the galvanostatic charge-discharge rate performance (50 to $1000 \mathrm{~mA} \mathrm{~g}^{-1}$ ) and long cycling test of Li-S batteries at $200 \mathrm{~mA} \mathrm{~g}^{-1}$, which were performed in the voltage range of 1.8 to $2.7 \mathrm{~V}$. A ZIVE SP1 electrochemical workstation was used for cyclic voltammetry $(\mathrm{CV})$ and electrochemical impedance spectroscopy (EIS) measurements. CV tests were performed in the voltage range of 1.8 to $2.7 \mathrm{~V}$. Potentiostatic EIS measurements were performed at open circuit voltage (OCV) in the frequency range of 1 to $10 \mathrm{MHz}$. Specific capacity measurements are within a $5 \%$ error limit. All electrochemical measurements were performed at room temperature $\left(\sim 25^{\circ} \mathrm{C}\right)$.

\section{Conclusions}

In summary, we demonstrated high-performance lithium-sulfur batteries based on a multidimensional sulfur-carbon cathode. The ultrasonic synthesis method in this case resulted in the generation of nanosulfur and its intercalation into the multilayered graphene 
nanoplatelets. MWCNT bundles were used as an additive to further improve the electrochemical performance. In addition to providing the increased electronic conductivity, graphene nanoplatelets act as a host for the incorporation of sulfur nanoparticles, and MWCNT bundles double up as polysulfide trap. A Li-S battery based on the optimized hybrid cathode exhibited an excellent specific capacity, rate performance, coulombic efficiency and cycling stability compared to CNT-free composite electrodes. Electrochemical and post-cycling analysis confirmed that both graphene nanoplatelets and MWCNT play a crucial role in improving the performance of the Li-S battery system. Improved electrochemical performances are attributed to the nanosulfur encapsulation between the layers of graphene nanoplatelets and trapping of polysulfides by MWCNT bundles. The multidimensional graphene-sulfur-MWCNT hybrid cathode presented here is a promising cathode for high-performance Li-S batteries.

Supplementary Materials: The following are available online at https:/ /www.mdpi.com/article/ 10.3390/batteries7020026/s1, Figure S1: FTIR spectrum of multilayered graphene nanoplatelets, Figure S2: XRD patterns of sulfur graphene nanoplatelets and GNS58, Figure S3: SEM images of graphene nanoplatelets, Figure S4: First and second galvanostatic profiles of GNS58 and GNS58CNT10 cathode, Figure S5: Galvanostatic rate performance of CNT-containing and reference sulfur hybrid cathodes, Figure S6: Voltage profiles of reference sulfur hybrid electrodes containing carbon particles and graphene nanoplatelets.

Author Contributions: Á.D. and V.E. conceptualized the idea. Á.D. and Á.M.-M. performed the materials synthesis and characterization. Á.D. and V.E. wrote the manuscript. V.E. also performed supervision of the work. All authors have read and agreed to the published version of the manuscript.

Funding: We thank IMDEA Materials Institute for their generous start-up funding. Vinodkumar Etacheri acknowledges the Spanish Ministry of Economy, Industry and Competitiveness (MINECO), Spanish Ministry of Science and Innovation, and Comunidad de Madrid for Juan de la Cierva fellowship (IJCI-2015-25488), Retos investigacion project (MAT2017-84002-C2-2-R)/Ramon y Cajal fellowship (RYC-2018-025893-I), and Talent attraction fellowship (2016-T1/IND-1300)/Youth employment initiative program (PEJD-2018-PRE/IND-8550), respectively.

Institutional Review Board Statement: Not applicable.

Informed Consent Statement: Not applicable.

Data Availability Statement: The data presented in this study are available on request from the corresponding author.

Acknowledgments: The authors thank Manuel Avella of IMDEA Materials Institute for TEM images acquisition and María Dolores Marqués of the Central Research Service (SCAI) at the University of Málaga for performing the BET analysis.

Conflicts of Interest: The authors declare no conflict of interest.

\section{References}

1. Larcher, D.; Tarascon, J.-M. Towards greener and more sustainable batteries for electrical energy storage. Nat. Chem. 2015, 7, 19-29. [CrossRef]

2. Dunn, B.; Kamath, H.; Tarascon, J.-M. Electrical Energy Storage for the Grid: A Battery of Choices. Science 2011, 334, 928-935. [CrossRef]

3. Chu, S.; Cui, Y.; Liu, S.C.N. The path towards sustainable energy. Nat. Mater. 2017, 16, 16-22. [CrossRef]

4. Scrosati, B. History of lithium batteries. J. Solid State Electrochem. 2011, 15, 1623-1630. [CrossRef]

5. Fotouhi, A.; Auger, D.J.; Propp, K.; Longo, S.; Wild, M. A review on electric vehicle battery modelling: From Lithium-ion toward Lithium-Sulphur. Renew. Sustain. Energy Rev. 2016, 56, 1008-1021. [CrossRef]

6. Etacheri, V.; Marom, R.; Elazari, R.; Salitra, G.; Aurbach, D. Challenges in the development of advanced Li-ion batteries: A review. Energy Environ. Sci. 2011, 4, 3243-3262. [CrossRef]

7. Li, M.; Lu, J.; Chen, Z.; Amine, K. 30 Years of Lithium-Ion Batteries. Adv. Mater. 2018, 30, e1800561. [CrossRef]

8. Tarascon, J.-M.; Armand, M. Issues and challenges facing rechargeable lithium batteries. Nat. Cell Biol. 2001, 414, 359-367. [CrossRef] [PubMed]

9. Manthiram, A.; Fu, Y.; Chung, S.-H.; Zu, C.; Su, Y.-S. Rechargeable Lithium-Sulfur Batteries. Chem. Rev. 2014, 114, 11751-11787. [CrossRef] [PubMed] 
10. Ji, X.; Nazar, L.F. Advances in Li-S batteries. J. Mater. Chem. 2010, 20, 9821-9826. [CrossRef]

11. Bini, M.; Capsoni, D.; Ferrari, S.; Quartarone, E.; Mustarelli, P. Rechargeable lithium batteries: Key scientific and technological challenges. In Rechargeable Lithium Batteries from Fundamentals to Applications; Elsevier: Amsterdam, The Netherlands, 2015; pp. 1-17.

12. Manthiram, A.; Fu, Y.; Su, Y.-S. Challenges and Prospects of Lithium-Sulfur Batteries. Acc. Chem. Res. 2013, 46, 1125-1134. [CrossRef]

13. Yin, Y.-X.; Xin, S.; Guo, Y.-G.; Wan, L.-J. Lithium-Sulfur Batteries: Electrochemistry, Materials, and Prospects. Angew. Chem. Int. Ed. 2013, 52, 13186-13200. [CrossRef]

14. Manthiram, A.; Chung, S.-H.; Zu, C. Lithium-Sulfur Batteries: Progress and Prospects. Adv. Mater. 2015, 27, 1980-2006. [CrossRef]

15. Mikhaylik, Y.V.; Akridge, J.R. Polysulfide Shuttle Study in the Li/S Battery System. J. Electrochem. Soc. 2004, 151, A1969-A1976. [CrossRef]

16. Haag, M.R. Handbook of Chemistry, 3rd ed.; McGraw-Hill: New York, NY, USA, 1950.

17. Chen, L.; Shaw, L.L. Recent advances in lithium-sulfur batteries. J. Power Sources 2014, 267, 770-783. [CrossRef]

18. Li, Z.; Yuan, L.; Yi, Z.; Sun, Y.; Liu, Y.; Jiang, Y.; Shen, Y.; Xin, Y.; Zhang, Z.; Huang, Y. Insight into the Electrode Mechanism in Lithium-Sulfur Batteries with Ordered Microporous Carbon Confined Sulfur as the Cathode. Adv. Energy Mater. 2014, 4, 1301473. [CrossRef]

19. Rosenman, A.; Markevich, E.; Salitra, G.; Aurbach, D.; Garsuch, A.; Chesneau, F.F. Review on Li-Sulfur Battery Systems: An Integral Perspective. Adv. Energy Mater. 2015, 5, 1500212. [CrossRef]

20. Su, Y.-S.; Manthiram, A. Lithium-sulphur batteries with a microporous carbon paper as a bifunctional interlayer. Nat. Commun. 2012, 3, 1166. [CrossRef] [PubMed]

21. Seh, Z.W.; Li, W.; Cha, J.J.; Zheng, G.; Yang, Y.; McDowell, M.T.; Hsu, P.-C.; Cui, Y. Sulphur-TiO 2 yolk-shell nanoarchitecture with internal void space for long-cycle lithium-sulphur batteries. Nat. Commun. 2013, 4, 1331. [CrossRef]

22. Suo, L.; Hu, Y.-S.; Li, H.; Armand, M.; Chen, L. A new class of Solvent-in-Salt electrolyte for high-energy rechargeable metallic lithium batteries. Nat. Commun. 2013, 4, 1481. [CrossRef]

23. Zhang, K.; Wang, L.; Cai, W.; Wang, C.; Li, G.; Li, Z.P.; Mao, W.; Qian, Y. A novel class of functional additives for cyclability enhancement of the sulfur cathode in lithium sulfur batteries. Inorg. Chem. Front. 2018, 5, 2013-2017. [CrossRef]

24. Hong, C.N.; Kye, D.K.; Mane, A.U.; Elam, J.W.; Etacheri, V.; Pol, V.G. Blocking Polysulfides in Graphene-Sulfur Cathodes of Lithium-Sulfur Batteries through Atomic Layer Deposition of Alumina. Energy Technol. 2019, 7, 1900621. [CrossRef]

25. Cheng, H.; Wang, S.; Tao, D.; Wang, M. Sulfur/Co3O4 nanotube composite with high performances as cathode materials for lithium sulfur batteries. Funct. Mater. Lett. 2014, 7, 1450020. [CrossRef]

26. Yu, M.; Ma, J.; Song, H.; Wang, A.; Tian, F.; Wang, Y.; Qiu, H.; Wang, R. Atomic layer deposited TiO2on a nitrogen-doped graphene/sulfur electrode for high performance lithium-sulfur batteries. Energy Environ. Sci. 2016, 9, 1495-1503. [CrossRef]

27. Ding, B.; Yuan, C.; Shen, L.; Xu, G.; Nie, P.; Zhang, X. Encapsulating Sulfur into Hierarchically Ordered Porous Carbon as a High-Performance Cathode for Lithium-Sulfur Batteries. Chem. A Eur. J. 2012, 19, 1013-1019. [CrossRef] [PubMed]

28. Zhang, K.; Zhao, Q.; Tao, Z.; Chen, J. Composite of sulfur impregnated in porous hollow carbon spheres as the cathode of Li-S batteries with high performance. Nano Res. 2013, 6, 38-46. [CrossRef]

29. Li, N.-W.; Yin, Y.-X.; Guo, Y.-G. Three-dimensional sandwich-type graphene@microporous carbon architecture for lithium-sulfur batteries. RSC Adv. 2015, 6, 617-622. [CrossRef]

30. Wei, W.; Wang, J.; Zhou, L.; Yang, J.; Schumann, B.; Nuli, Y. CNT enhanced sulfur composite cathode material for high rate lithium battery. Electrochem. Commun. 2011, 13, 399-402. [CrossRef]

31. Evers, S.; Nazar, L.F. Graphene-enveloped sulfur in a one pot reaction: A cathode with good coulombic efficiency and high practical sulfur content. Chem. Commun. 2012, 48, 1233-1235. [CrossRef]

32. Ji, X.; Lee, K.T.; Nazar, L.F. A highly ordered nanostructured carbon-sulphur cathode for lithium-sulphur batteries. Nat. Mater. 2009, 8, 500-506. [CrossRef]

33. Jozwiuk, A.; Sommer, H.; Janek, J.; Brezesinski, T. Fair performance comparison of different carbon blacks in lithium-sulfur batteries with practical mass loadings-Simple design competes with complex cathode architecture. J. Power Sources 2015, 296, 454-461. [CrossRef]

34. Zhang, B.; Lai, C.; Zhou, Z.; Gao, X. Preparation and electrochemical properties of sulfur-acetylene black composites as cathode materials. Electrochim. Acta 2009, 54, 3708-3713. [CrossRef]

35. Li, X.; Cao, Y.; Qi, W.; Saraf, L.V.; Xiao, J.; Nie, Z.; Mietek, J.; Zhang, J.-G.; Schwenzer, B.; Liu, J. Optimization of mesoporous carbon structures for lithium-sulfur battery applications. J. Mater. Chem. 2011, 21, 16603-16610. [CrossRef]

36. Huang, J.-Q.; Liu, X.-F.; Zhang, Q.; Chen, C.-M.; Zhao, M.-Q.; Zhang, S.-M.; Zhu, W.; Qian, W.-Z.; Wei, F. Entrapment of sulfur in hierarchical porous graphene for lithium-sulfur batteries with high rate performance from -40 to $60{ }^{\circ} \mathrm{C}$. Nano Energy 2013, 2, 314-321. [CrossRef]

37. Jung, D.S.; Hwang, T.H.; Lee, J.H.; Koo, H.Y.; Shakoor, R.A.; Kahraman, R.; Jo, Y.N.; Park, M.-S.; Choi, J.W. Hierarchical Porous Carbon by Ultrasonic Spray Pyrolysis Yields Stable Cycling in Lithium-Sulfur Battery. Nano Lett. 2014, 14, 4418-4425. [CrossRef]

38. Jayaprakash, N.; Shen, J.; Moganty, S.S.; Corona, A.; Archer, L.A. Porous Hollow Carbon@Sulfur Composites for High-Power Lithium-Sulfur Batteries. Angew. Chem. Int. Ed. 2011, 50, 5904-5908. [CrossRef] [PubMed] 
39. Zhang, B.; Qin, X.; Li, G.R.; Gao, X.P. Enhancement of long stability of sulfur cathode by encapsulating sulfur into micropores of carbon spheres. Energy Environ. Sci. 2010, 3, 1531-1537. [CrossRef]

40. Zhang, C.; Bin Wu, H.; Yuan, C.; Guo, Z.; Lou, X.W. (David). Confining Sulfur in Double-Shelled Hollow Carbon Spheres for Lithium-Sulfur Batteries. Angew. Chem. Int. Ed. 2012, 51, 9592-9595. [CrossRef] [PubMed]

41. Zhou, G.; Wang, D.-W.; Li, F.; Hou, P.-X.; Yin, L.; Liu, C.; Lu, G.Q.; Gentle, I.R.; Cheng, H.-M. A flexible nanostructured sulphur-carbon nanotube cathode with high rate performance for Li-S batteries. Energy Environ. Sci. 2012, 5, 8901-8906. [CrossRef]

42. Cheng, X.-B.; Huang, J.-Q.; Zhang, Q.; Peng, H.-J.; Zhao, M.-Q.; Wei, F. Aligned carbon nanotube/sulfur composite cathodes with high sulfur content for lithium-sulfur batteries. Nano Energy 2014, 4, 65-72. [CrossRef]

43. Han, S.-C.; Song, M.-S.; Lee, H.; Kim, H.-S.; Ahn, H.-J.; Lee, J.-Y. Effect of Multiwalled Carbon Nanotubes on Electrochemical Properties of Lithium/Sulfur Rechargeable Batteries. J. Electrochem. Soc. 2003, 150, A889-A893. [CrossRef]

44. Yuan, L.; Yuan, H.; Qiu, X.; Chen, L.; Zhu, W. Improvement of cycle property of sulfur-coated multi-walled carbon nanotubes composite cathode for lithium/sulfur batteries. J. Power Sources 2009, 189, 1141-1146. [CrossRef]

45. Zhou, G.; Pei, S.; Li, L.; Wang, D.-W.; Wang, S.; Huang, K.; Yin, L.-C.; Li, F.; Cheng, H.-M. A Graphene-Pure-Sulfur Sandwich Structure for Ultrafast, Long-Life Lithium-Sulfur Batteries. Adv. Mater. 2014, 26, 625-631. [CrossRef] [PubMed]

46. Wang, J.-Z.; Lu, L.; Choucair, M.; Stride, J.A.; Xu, X.; Liu, H.-K. Sulfur-graphene composite for rechargeable lithium batteries. J. Power Sources 2011, 196, 7030-7034. [CrossRef]

47. Park, M.-S.; Yu, J.-S.; Kim, K.J.; Jeong, G.; Kim, J.-H.; Jo, Y.-N.; Hwang, U.; Kang, S.; Woo, T.; Kim, Y.-J. One-step synthesis of a sulfur-impregnated graphene cathode for lithium-sulfur batteries. Phys. Chem. Chem. Phys. 2012, 14, 6796-6804. [CrossRef]

48. Wang, H.; Yang, Y.; Liang, Y.; Robinson, J.T.; Li, Y.; Jackson, A.; Cui, Y.; Dai, H. Graphene-Wrapped Sulfur Particles as a Rechargeable Lithium-Sulfur Battery Cathode Material with High Capacity and Cycling Stability. Nano Lett. 2011, 11, $2644-2647$. [CrossRef]

49. Ji, L.; Rao, M.; Zheng, H.; Zhang, L.; Li, Y.; Duan, W.; Guo, J.; Cairns, E.J.; Zhang, Y. Graphene Oxide as a Sulfur Immobilizer in High Performance Lithium/Sulfur Cells. J. Am. Chem. Soc. 2011, 133, 18522-18525. [CrossRef]

50. Kumar, G.G.; Chung, S.-H.; Kumar, T.R.; Manthiram, A. Three-Dimensional Graphene-Carbon Nanotube-Ni Hierarchical Architecture as a Polysulfide Trap for Lithium-Sulfur Batteries. ACS Appl. Mater. Interfaces 2018, 10, 20627-20634. [CrossRef]

51. He, J.; Chen, Y.; Li, P.; Fu, F.; Wang, Z.; Zhang, W. Three-dimensional CNT/graphene-sulfur hybrid sponges with high sulfur loading as superior-capacity cathodes for lithium-sulfur batteries. J. Mater. Chem. A 2015, 3, 18605-18610. [CrossRef]

52. Tang, C.; Zhang, Q.; Zhao, M.-Q.; Huang, J.-Q.; Cheng, X.-B.; Tian, G.-L.; Peng, H.-J.; Wei, F. Nitrogen-Doped Aligned Carbon Nanotube/Graphene Sandwiches: Facile Catalytic Growth on Bifunctional Natural Catalysts and Their Applications as Scaffolds for High-Rate Lithium-Sulfur Batteries. Adv. Mater. 2014, 26, 6100-6105. [CrossRef]

53. Peng, H.-J.; Huang, J.-Q.; Zhao, M.-Q.; Zhang, Q.; Cheng, X.-B.; Liu, X.-Y.; Qian, W.-Z.; Wei, F. Nanoarchitectured Graphene/CNT@Porous Carbon with Extraordinary Electrical Conductivity and Interconnected Micro/Mesopores for Lithium-Sulfur Batteries. Adv. Funct. Mater. 2014, 24, 2772-2781. [CrossRef]

54. Zhao, M.-Q.; Liu, X.-F.; Zhang, Q.; Tian, G.-L.; Huang, J.-Q.; Zhu, W.; Wei, F. Graphene/Single-Walled Carbon Nanotube Hybrids: One-Step Catalytic Growth and Applications for High-Rate Li-S Batteries. ACS Nano 2012, 6, 10759-10769. [CrossRef]

55. Lin, C.-Y.; Zhao, Z.; Niu, J.; Xia, Z. Synthesis, properties and applications of 3D carbon nanotube-graphene junctions. J. Phys. D Appl. Phys. 2016, 49, 443001. [CrossRef]

56. Gao, F. Graphene/Carbon Nanotubes Composite as a Polysulfide Trap for Lithium-Sulfur Batteries. Int. J. Electrochem. Sci. 2019, 14, 3301-3314. [CrossRef]

57. Li, Z.; Huang, Y.; Yuan, L.; Hao, Z.; Huang, Y. Status and prospects in sulfur-carbon composites as cathode materials for rechargeable lithium-sulfur batteries. Carbon 2015, 92, 41-63. [CrossRef]

58. Cao, Y.; Li, M.; Liu, J.; Amine, K. Bridging the academic and industrial metrics for next-generation practical batteries. Nat. Nanotechnol. 2019, 14, 200-207. [CrossRef]

59. Hagen, M.; Dörfler, S.; Fanz, P.; Berger, T.; Speck, R.; Tübke, J.; Althues, H.; Hoffmann, M.; Scherr, C.; Kaskel, S. Development and costs calculation of lithium-sulfur cells with high sulfur load and binder free electrodes. J. Power Sources 2013, 224, 260-268. [CrossRef]

60. Weng, W.; Pol, V.G.; Amine, K. Ultrasound Assisted Design of Sulfur/Carbon Cathodes with Partially Fluorinated Ether Electrolytes for Highly Efficient Li/S Batteries. Adv. Mater. 2013, 25, 1608-1615. [CrossRef]

61. Suslick, K.S. Sonochemistry. Science 1990, 247, 1439-1445. [CrossRef]

62. Bang, J.H.; Suslick, K.S. Applications of Ultrasound to the Synthesis of Nanostructured Materials. Adv. Mater. 2010, 22, 1039-1059. [CrossRef] [PubMed]

63. McNamara, W.B.; Didenko, Y.T.; Suslick, K.S. Sonoluminescence temperatures during multi-bubble cavitation. Nat. Cell Biol. 1999, 401, 772-775. [CrossRef]

64. Awati, P.; Awate, S.; Shah, P.; Ramaswamy, V. Photocatalytic decomposition of methylene blue using nanocrystalline anatase titania prepared by ultrasonic technique. Catal. Commun. 2003, 4, 393-400. [CrossRef]

65. Dysart, A.D.; Burgos, J.C.; Mistry, A.; Chen, C.-F.; Liu, Z.; Hong, C.N.; Balbuena, P.B.; Mukherjee, P.P.; Pol, V.G. Towards Next Generation Lithium-Sulfur Batteries: Non-Conventional Carbon Compartments/Sulfur Electrodes and Multi-Scale Analysis. J. Electrochem. Soc. 2016, 163, A730-A741. [CrossRef] 
66. Yu, X.; Manthiram, A. Electrode-Electrolyte Interfaces in Lithium-Sulfur Batteries with Liquid or Inorganic Solid Electrolytes. Accounts Chem. Res. 2017, 50, 2653-2660. [CrossRef]

67. Yu, M.; Li, R.; Wu, M.; Shi, G. Graphene materials for lithium-sulfur batteries. Energy Storage Mater. 2015, 1, 51-73. [CrossRef]

68. Yuan, G.; Wang, G.; Wang, H.; Bai, J. A novel three-dimensional sulfur/graphene/carbon nanotube composite prepared by a hydrothermal co-assembling route as binder-free cathode for lithium-sulfur batteries. J. Nanoparticle Res. 2015, 17, 36. [CrossRef]

69. Papandrea, B.; Xu, X.; Xu, Y.; Chen, C.-Y.; Lin, Z.; Wang, G.; Luo, Y.; Liu, M.; Huang, Y.; Mai, L.; et al. Three-dimensional graphene framework with ultra-high sulfur content for a robust lithium-sulfur battery. Nano Res. 2016, 9, 240-248. [CrossRef]

70. Chen, Y.; Lu, S.; Wu, X.; Liu, J. Flexible Carbon Nanotube-Graphene/Sulfur Composite Film: Free-Standing Cathode for High-Performance Lithium/Sulfur Batteries. J. Phys. Chem. C 2015, 119, 10288-10294. [CrossRef]

71. Zhang, Z.; Kong, L.-L.; Liu, S.; Li, G.-R.; Gao, X.-P. A High-Efficiency Sulfur/Carbon Composite Based on 3D Graphene Nanosheet@Carbon Nanotube Matrix as Cathode for Lithium-Sulfur Battery. Adv. Energy Mater. 2017, 7, 1602543. [CrossRef]

72. Rehman, S.; Khan, K.; Zhao, Y.; Hou, Y. Nanostructured cathode materials for lithium-sulfur batteries: Progress, challenges and perspectives. J. Mater. Chem. A 2017, 5, 3014-3038. [CrossRef]

73. Warren, B.E.; Burwell, J.T. The Structure of Rhombic Sulphur. J. Chem. Phys. 1935, 3, 6-8. [CrossRef]

74. Iijima, S. Electron Microscopy of Small Particles. QJM Int. J. Med. 1985, 34, 249-265. [CrossRef]

75. Siegel, R.W.; Trigg, G.L. Nanophase Materials. In Encyclopedia of Applied Physics; Trigg, G.L., Ed.; Wiley-VCH: Weinheim, Germany, 1994; pp. 1-27.

76. Popova, A.N. Crystallographic analysis of graphite by X-Ray diffraction. Coke Chem. 2017, 60, 361-365. [CrossRef]

77. Ferrari, A.C.; Meyer, J.C.; Scardaci, V.; Casiraghi, C.; Lazzeri, M.; Mauri, F.; Piscanec, S.; Jiang, D.; Novoselov, K.S.; Roth, S.; et al. Raman Spectrum of Graphene and Graphene Layers. Phys. Rev. Lett. 2006, 97, 187401. [CrossRef]

78. Suslick, K.S.; Price, G.J. Applications of ultrasound to materials chemistry. Annu. Rev. Mater. Res. 1999, 29, 295-326. [CrossRef]

79. Ward, A.T. Raman spectroscopy of sulfur, sulfur-selenium, and sulfur-arsenic mixtures. J. Phys. Chem. 1968, 72, 4133-4139. [CrossRef]

80. Sing, K.S. Characterization of porous solids: An introductory survey. Adv. Pharmacol. 1991, 62, 1-9. [CrossRef]

81. Fan, X.; Sun, W.; Meng, F.; Xing, A.; Liu, J. Advanced chemical strategies for lithium-sulfur batteries: A review. Green Energy Environ. 2018, 3, 2-19. [CrossRef]

82. Mi, Y.; Liu, W.; Li, X.; Zhuang, J.; Zhou, H.; Wang, H. High-performance Li-S battery cathode with catalyst-like carbon nanotube-MoP promoting polysulfide redox. Nano Res. 2017, 10, 3698-3705. [CrossRef] 